\title{
Evaluasi Jalur Evakuasi Bencana Kebakaran Pada Sirkulasi Gedung Serbaguna UNIB
}

\section{Evaluation of the Fire Disaster Evacuation Path in the UNIB Multipurpose Building Circulation}

\author{
Debby Seftyarizki $^{1, a)}$, Panji Anom Ramawangsa ${ }^{1)}$ \& Dwi Oktavallyan Saputri ${ }^{1)}$ \\ ${ }^{1)}$ Jurusan Arsitektur, Universitas Bengkulu, Kota Bengkulu.
}

Koresponden : ${ }^{\text {a) }}$ debby.seftyarizki@unib.ac.id

\begin{abstract}
ABSTRAK
Gedung Serba Guna (GSG) Universitas Bengkulu (UNIB) merupakan gedung yang difungsikan untuk kegiatan publik. Sebagai fasilitas publik, GSG hendaknya memiliki kenyamanan dan keamanan dalam hal penyelamatan terhadap bencana, salah satunya bahaya kebakaran. Jalur evakuasi merupakan salah satu faktor yang mempengaruhi optimasi proses penyelamatan. Pada GSG UNIB, jalur evakuasi bahaya kebakaran masih belum sepenuhnya dipahami. Oleh karena itu perlu dilakukan suatu evaluasi untuk mengetahui keefektifan penggunaannya dalam mengarahkan pengguna bangunan agar segera meninggalkan area berbahaya ketika terjadi bencana. Evaluasi yang dilakukan pada penelitian ini berupa pengamatan langsung pada GSG UNIB yang ditujukan untuk mengidentifikasi kelengkapan yang dimiliki berdasarkan standar dan peraturan-peraturan bangunan gedung yang berlaku terkait kondisi bahaya kebakaran. Secara umum hasil penelitian menunjukkan bahwa kondisi jalur evakuasi bencana kebakaran pada GSG UNIB telah cukup memenuhi standar, terutama pada area tangga, pintu, serta ketersediaan exhaust dan tanda penunjuk arah. Beberapa hal yang perlu menjadi perhatian adalah penambahan akses yang langung menuju area luar di lantai 2 , serta ketersediaan peralatan seperti detektor, alarm, hidran, sprinkler, tabung pemadam yang diperlukan kedepannya untuk untuk mengoptimalkan kenyamana, keamanan, dan kelancaran proses evakuasi sebagai upaya mitigasi di GSG UNIB ketika terjadi kebakaran.
\end{abstract}

Kata Kunci : manajemen infrastruktur dan fasilitas, evakuasi, kebakaran, gedung serba guna.

\section{PENDAHULUAN}

Bangunan gedung adalah wujud fisik hasil pekerjaan konstruksi yang digunakan untuk suatu aktivitas tertentu. Bangunan gedung yang digunakan oleh orang banyak secara bersamaan termasuk ke dalam bangunan publik. Dalam melakukan aktivitas di dalamnya, bangunan gedung untuk publik memerlukan rasa aman dan nyaman di setiap situasi, termasuk dalam hal penyelamatan terhadap bencana, salah satunya bahaya kebakaran. Bahaya kebakaran merupakan salah satu bahaya yang dapat mengancam dan berpotensi menimbulkan kerugian. Untuk meminimalisir beberapa dampak negatif akibat kebakaran, diperlukan adanya proses evakuasi.

Bangunan Gedung Serbaguna Universitas Bengkulu merupakan bangunan publik yang didalamnya mengandung berbagai fasilitas keselamatan dan kenyamanan. Sebagai infrastruktur dengan fasilitas, aset ini harus dikelola dengan baik sesuai dengan prinsip Manajemen Aset Infrastruktur \& Fasilitas. Aset harus dikelola unutk menghadapi segala bentuk resiko yang bisa terjadi, diantaranya resiko kebakaran (Soemitro \& Suprayitno 2018; Suprayitno \& Soemitro 2018). 
Menurut Peraturan Menteri Pekerjaan Umum No.26/PRT/M/2008, pada saat proses evakuasi, penghuni bangunan harus memiliki waktu yang cukup untuk meyelamatkan diri dengan aman dan meninggalkan gedung. Dalam penelitian yang dilakukan Andhika, Kasim, dan Hawibowo (2013), optimasi waktu evakuasi dipengaruhi oleh desain bangunan beserta jalur evakuasinya, jumlah orang yang dievakuasi, dan beberapa elemen pendukung yang sesuai standar terkait proses evakuasi. Dengan demikian, jalur sirkulasi merupakan salah satu sarana penyelamatan jiwa yang penting saat proses evakuasi. Seperti yang terdapat pada Permen PU no. 26 tahun 2008, SNI 03-1746-2000, dan SNI 03-6574-2001, dimana aspekaspek dalam jalur sirkulasi untuk evakuasi meliputi tangga darurat, pintu darurat, tanda petunjuk arah, sarana jalan keluar, penerangan darurat, dan pengendaliaan asap, perlu menjadi perhatian dalam perencanan, perancangan, serta pemeliharaan bangunan gedung.

Gedung Serba Guna (GSG) di Universitas Bengkulu (UNIB) merupakan salah satu bangunan yang berfungsi sebagai ruang pertunjukan, ruang komunal dan ruang bersama, yang difungsikan untuk kegiatan umum. GSG UNIB tidak hanya digunakan untuk kepentingan kampus saja, namun juga dapat mewadahi kegiatan non kampus seperti kegiatan pernikahan yang disewakan untuk masyarakat umum. Sebagai gedung yang sering digunakan untuk kegiatan berskala besar dan melibatkan orang banyak, GSG UNIB memerlukan kenyamanan dan keamanan dalam aspek sirkulasi untuk proses evakuasi, terutama saat terjadi bencana kebakaran. Kondisi beberapa sistem proteksi dan evakuasi kebakaran pada sirkulasi GSG UNIB perlu dikaji ulang untuk mengetahui seberapa optimal fungsinya dalam penyelematan jiwa pengguna bangunan.

Evaluasi jalur evakuasi bencana kebakaran pada sirkulasi GSG dikaji berdasarkan beberapa standar yang telah ditentukan, agar keamanan dan kenyaman pengguna bangunan dalam kondisi berbahaya tetap terjamin. Hasil evaluasi diharapkan dapat menjadi pertimbangan untuk perbaikan sekaligus menjadi dasar solusi desain area sirkulasi GSG UNIB yang lebih optimal untuk kelancaran, keamanan, kenyamanan, dan keselamatan pengguna bangunan saat proses evakuasi bencana terutama bahaya kebakaran.

Makalah ini menyampaikan hasil evaluasi jalur evakuasi bencana kebakaran pada sirkulasi GSG UNIB.

\section{TINJAUAN LITERATUR}

Penyelamatan saat terjadi bahaya kebakaran dapat dilakukan dengan merencanakan jalan keluar darurat yang aman beserta pemasangan perlengkapan dan peralatan pemadam kebakaran. Telah terdapat beberapa penelitian terkait proses evakuasi kebakaran, salah satunya penelitian yang dilakukan oleh Setiawan, Purnomo, dan Santoso pada tahun 2016, dimana tangga darurat menjadi objek penting dalam observasi untuk mengetahui kondisinya sesuai syarat dalam menghadapi kondisi bahaya kebakaran. Beberapa variable yang dievaluasi antara lain, dimensi tangga (lebar tangga, lebar pijakan, handrail), bahan material, dan kelengkapan lain seperti bukaan pintu darurat, ketersediaan pengeras suara, lampu, hydrant box, penunjuk arah exit dan tang darurat, dan sprinkler. Hasil pengamatan tersebut menunjukkan bahwa beberapa kondisi tangga dan kelengkapan evakuasi kebakaran di gedung-gedung di Universitas Negeri Semarang, masih belum memenuhi standar.

Penelitian lain terkait sistem proteksi kebakaran juga dilakukan oleh Kowari dan Martiana pada tahun 2017. Sistem proteksi kebakaran seperti alarm, detektor, sprinkler, APAR, hydrant, akses, pintu tahan api, jalan keluar, tangga darurat, tanda petunjuk keluar, pintu darurat, penerangan darurat, dan tempat berkumpul di PT. PJB UP Brantas Malang diobservasi dengan mengacu pada beberapa standar dan peraturan. Hasil penelitian menujukkan bahwa beberapa sistem proteksi kebakaran tersebut termasuk dalam kategori masih kurang memenuhi standar. 
Lebih detail, sarana penyelamatan sebagai upaya evakuasi bahaya kebakaran terdapat di Permen PU no.45, Permen PU no. 26, SNI 03-1746-2000, dan SNI 03-6574-2001, dengan detail sebagai berikut :

Tabel 1. Standar Sarana Penyelamatan Evakuasi Kebakaran

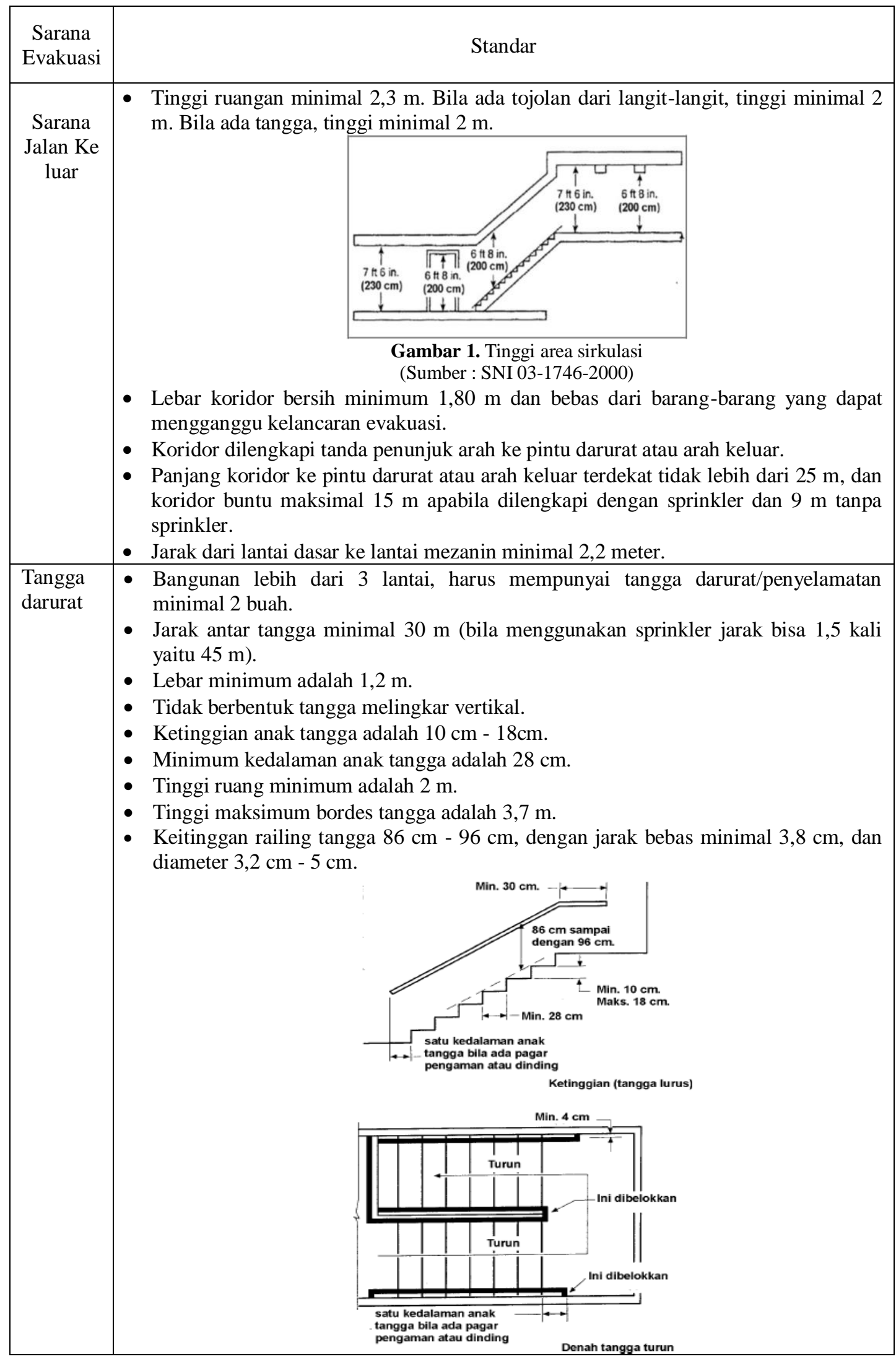









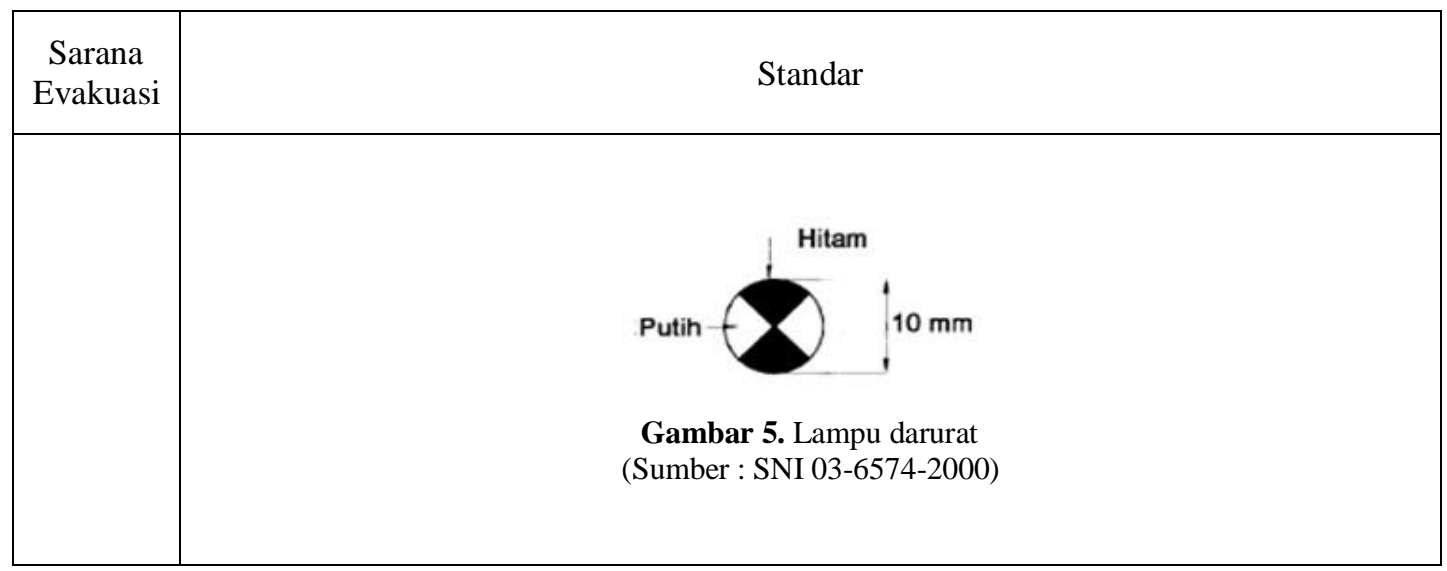

(Sumber : Permen PU no.45, Permen PU no. 26, SNI 03-1746-2000, dan SNI 03-6574-2001)

Kajian Adapun komponen lain yang perlu diperhatikan sebagai upaya pencegahan bahaya kebakaran dalam perencanaan seerti yang dipaparkan Frick, Heinz; dkk (2008) antara lain :

- Perlengkapan detektor asap, panas, dan api, serta tombol alarm kebakaran.

- Jalur keluar darurat kebakaran dengan ditempuh 20m - 50m tanpa halangan dan rintangan, dengan lebar pintu 1,2m. Lebar area tangga lebih dari 1,2m dan memiliki maksimal 15 anak tangga.

- Posisi jendela pada setiap elevasi lantai yang menggunakan sirip horizontal.

- Terdapat hidran di dekat tangga dan sprinkler dengan jarak $9 \mathrm{~m}-12 \mathrm{~m}$.

- Terdapat pompa pemadam dan tabung pemadam.

- Terdapat exhauster asap dan udara panas.

\section{METODOLOGI PENELITIAN}

Metode yang digunakan dalam penelitian ini berupa observasi pada Gedung Serba Guna Universita Bengkulu. Adapun objek yang diamati terbatas hanya pada sirkulasi jalur evakuasi bencana kebakaran, yaitu berupa sarana jalan ke luar, tangga darurat, pintu, tanda penunjuk arah, lampu, serta perlengkapan bahya kebakaran lainnya seperti alarm kebakaran, detektor api, hidrant, sprinkler, dan tombol alarm kebakaran. Berbagai objek yang diamati tersebut kemudian akan diidentifikasi keberadaannya, untuk kemudian dideskripsikan kesesuaian kondisinya seperti letaknya, jumlahnya, dimensi, dan ketentuan lainnya berdasarkan Permen PU no. 26, Permen PU no.45, SNI 03-1746-2000, SNI 03-6574-2001, dan tinjauan pustaka oleh Frick, Heinz; dkk (2008) yang telah disebutkan di bab sebelumnya.

\section{HASIL DAN DISKUSI}

Gedung Serba Guna UNIB memiliki luas $2.400 \mathrm{~m} 2$ pada lantai dasar. Ruang utama memiliki panggung di sisi beakang, dan terdapat terdapat balkon lantai 2 di sekeliling area samping kiri, kanan, dan depan ruang auditorium. Balkon di lantai 2 merupkan tempat duduk bertingkat (tribun) yang dicor beton. Dengan luas total ruang $3.000 \mathrm{~m} 2$ di ruang utama, GSG UNIB bisa menampung hingga 1000 orang. Selain ruang utama, GSG Unib juga memiliki ruang lain berupa ruang rapat di bagian depan gedung, ruang persiapan, toilet, dan gudang di bagian belakang dekat panggung. Terdapat pula ruang-ruang kecil yang bisa digunakan untuk kegiatan mahasiswa pada lantai 2 di bagian belakang bangunan. Namun, fokus area yang diobservasi hanyalah pada area ruang utama GSG UNIB. 

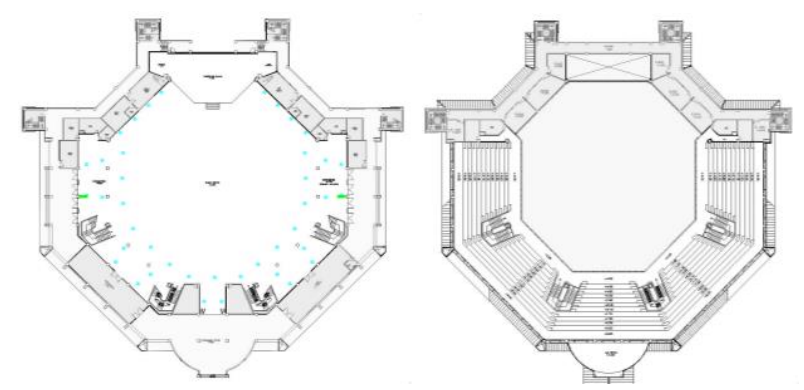

Gambar 6. Denah GSG UNIB beserta perletakan exhaust dan tanda penunjuk arah (Sumber: Universitas Bengkulu)

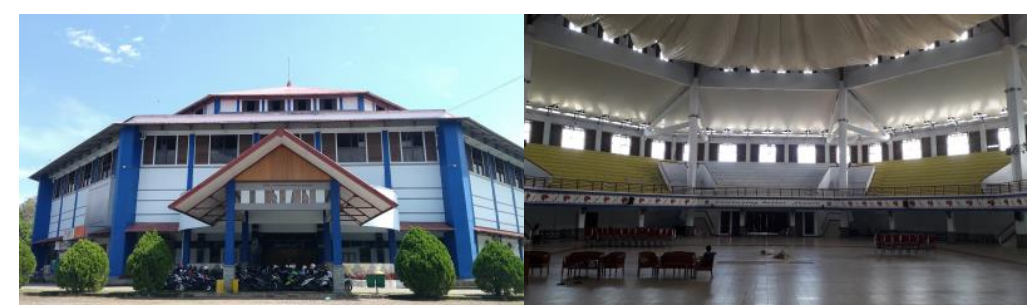

Gambar 7. Foto tampak luar dan bagian dalam ruang utama GSG UNIB (Sumber: Penulis)

Berdasarkan hasil pengamatan, GSG UNIB telah memiliki beberapa sarana penyelamatan bahaya kebakaran seperti tangga, pintu, exhaust, dan tanda penunjuk ke luar. Namun, GSG UNIB masih belum memiliki beberapa kelengkapan seperti tombol alarm kebakaran, lampu darurat, hidran, sprinkler, tabung pemadam, serta detektor asap, panas, dan api.

Tabel 2. Ketersediaan Sarana Evakuasi Kebakaran pada GSG UNIB

\begin{tabular}{|l|c|}
\hline \multicolumn{2}{|c|}{ Ketersediaan Sarana Evakuasi Kebakaran } \\
\hline Tangga & Ada \\
\hline Pintu & Ada \\
\hline Tanda Penunjuk arah & Ada \\
\hline Tombol alarm kebakaran & Tidak Ada \\
\hline Lampu darurat & Tidak Ada \\
\hline Hidran & Tidak Ada \\
\hline Sprinkler & Tidak Ada \\
\hline Tabung pemadam & Tidak Ada \\
\hline $\begin{array}{l}\text { Detektor asap, panas, dan } \\
\text { api }\end{array}$ & Tidak Ada \\
\hline Exhaust & Ada \\
\hline
\end{tabular}

(Sumber : Penulis) 


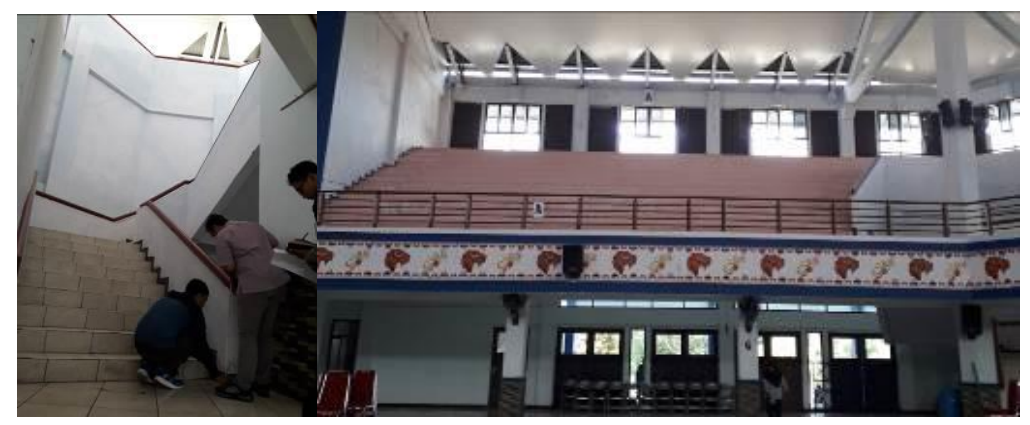

Gambar 8. Tangga dan pencapaian terjauh di balkon lt. 2 (Sumber: Penulis)

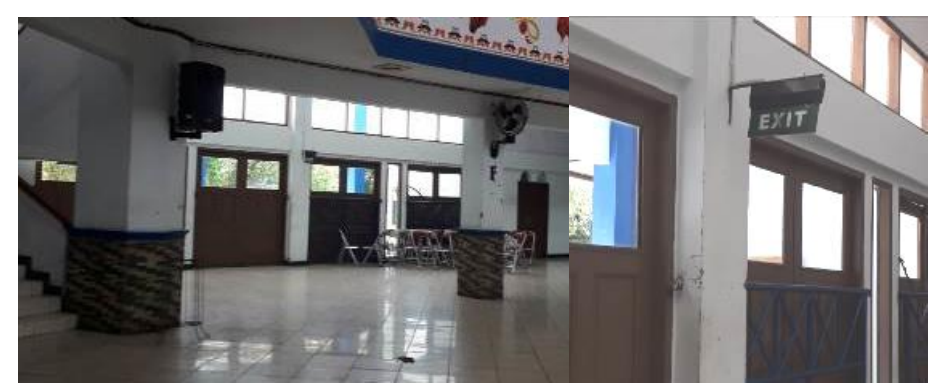

Gambar 9. Pintu ke luar dan tanda "EXIT" (Sumber: Penulis)

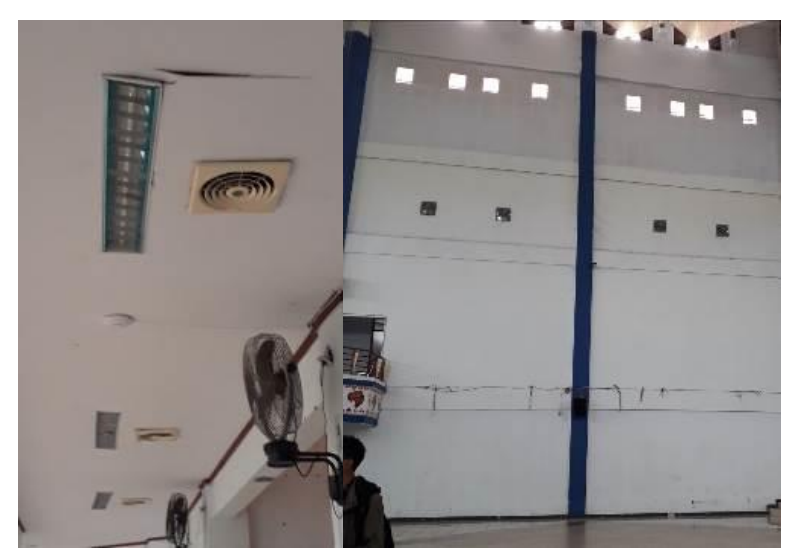

Gambar 10. Exhaust di GSG UNIB (Sumber: Penulis)

Ruang utama GSG UNIB memiliki tiga akses masuk di tiga sisi bangunan, yaitu di sisi depan, serta samping kanan dan kiri. Pintu bagian depan merupakan pintu lipat dari material kayu setinggi $2,5 \mathrm{~m}$ yang dibuka ke dua sisi nya dengan lebar 4,85 m. Sementara pintu di bagian samping kiri dan kanan masing-masing terdiri dari 4 buah. Setiap pintu memiliki 2 buah daun pintu dengan material kayu, dan terdapat kaca di bagian atasnya. Setiap pintu memiliki lebar $2 \mathrm{~m}$ dan tinggi 2,5 $\mathrm{m}$ dengan bukaan ke arah luar. Jangkauan terjauh pintu dari bagian tengah ruang utama GSG adalah $25 \mathrm{~m}$, sementara jarak antara tangga dan pintu terdekat adalah $6 \mathrm{~m}$.

Pintu di bagian kiri dan kanan bangunan GSG UNIB telah dilengkapi dengan satu buah tanda penunjuk arah ke luar berupa tulisan "EXIT" di atas pintu. Bentuk denah yang tidak rumit membuat tanda "EIXIT" tersebut dapat di lihat dengan mudah.

Bagian dalam ruang utama GSG UNIB memiliki 4 buah tangga beton dengan finishing keramik sebagai sirkulasi ke balkon lantai 2. Ke-empat tangga tersebut letaknya tersebar 
dengan jarak antar tangga adalah 16 - $19 \mathrm{~m}$. Sementara area balkon dengan jangkauan terjauh yaitu di sudut balkon adalah sepanjang $16 \mathrm{~m}$. Tangga berbentuk "U", memiliki lebar 1,2 m dengan total 21 anak tangga termasuk 2 bordes. Ketinggian anak tangga $16 \mathrm{~cm}-17 \mathrm{~cm}$, dan kedalaman $30 \mathrm{~cm}$ termasuk step nosing $5 \mathrm{~cm}$ di ujungnya. Di sisi kiri dan kanan tangga terdapat railing setinggi $90 \mathrm{~cm}$ dari bata yang diplester, dan besi diameter $10 \mathrm{~cm}$ di bagian paling atasnya. Tangga tribun di area balkon lantai 2 memiliki lebar $1 \mathrm{~m}$ dan ketinggian anak tangga $20 \mathrm{~cm}-25 \mathrm{~cm}$, serta terdapat railing di salah satu sisinya.

Untuk membantu pengkondisian udara di dalam ruang utama GSG UNIB, terdapat exhaust yang letaknya tersebar di sekeliling ruangan. Masing-masing sisi kiri dan kanan dinding dekat panggungn memiliki 4 buah exhaust di ketinggian $11 \mathrm{~m}$. serta 13 kipas exhaust yang tersebar di atas plafond di bawah area tribun lantai 2 .

Tabel 3. Kondisi Sarana Evakuasi Kebakaran yang tersedia di GSG UNIB

\begin{tabular}{|c|c|c|}
\hline Objek & Kondisi & Kesesuaian \\
\hline \multirow[t]{10}{*}{ Pintu } & $\begin{array}{l}\text { Lebar bukaan }=1 \mathrm{~m}- \\
4,85 \mathrm{~m}\end{array}$ & $\begin{array}{l}\text { Memenuhi } \\
\text { standar }\end{array}$ \\
\hline & Membuka ke arah luar & $\begin{array}{l}\text { Memenuhi } \\
\text { standar }\end{array}$ \\
\hline & $\begin{array}{l}\text { Langsung menuju area } \\
\text { luar bangunan }\end{array}$ & $\begin{array}{l}\text { Memenuhi } \\
\text { standar }\end{array}$ \\
\hline & $\begin{array}{l}\text { Tidak ada tuas / tungkai } \\
\text { pembuka }\end{array}$ & $\begin{array}{l}\text { Belum } \\
\text { memenuhi } \\
\text { standar }\end{array}$ \\
\hline & Memiliki kaca & $\begin{array}{l}\text { Memenuhi } \\
\text { standar }\end{array}$ \\
\hline & Material kayu & $\begin{array}{l}\text { Belum } \\
\text { memenuhi } \\
\text { standar }\end{array}$ \\
\hline & Warna cokelat & $\begin{array}{l}\text { Belum } \\
\text { memenuhi } \\
\text { standar }\end{array}$ \\
\hline & $\begin{array}{l}\text { Tidak memiliki penutup } \\
\text { otomatis }\end{array}$ & $\begin{array}{l}\text { Belum } \\
\text { memenuhi } \\
\text { standar }\end{array}$ \\
\hline & $\begin{array}{l}\text { Jarak pencapaian }=25 \mathrm{~m} \\
-6 \mathrm{~m}\end{array}$ & $\begin{array}{l}\text { Memenuhi } \\
\text { standar }\end{array}$ \\
\hline & $\begin{array}{l}\text { Jalan ke luar tidak terha } \\
\text { langi benda-benda }\end{array}$ & $\begin{array}{l}\text { Memenuhi } \\
\text { standar }\end{array}$ \\
\hline \multirow[t]{2}{*}{$\begin{array}{l}\text { Penunjuk } \\
\text { arah }\end{array}$} & Di atas pintu keluar & $\begin{array}{l}\text { Memenuhi } \\
\text { standar }\end{array}$ \\
\hline & $\begin{array}{l}\text { Terbaca dari jarak } 12 \mathrm{~m} \\
-30 \mathrm{~m}\end{array}$ & $\begin{array}{l}\text { Memenuhi } \\
\text { standar }\end{array}$ \\
\hline \multirow[t]{7}{*}{ Tangga } & Berbentuk U & $\begin{array}{l}\text { Memenuhi } \\
\text { standar }\end{array}$ \\
\hline & Lebar $=180 \mathrm{~cm}$ & $\begin{array}{l}\text { Memenuhi } \\
\text { standar }\end{array}$ \\
\hline & $\begin{array}{l}\text { Tinggi anak tangga }=16 \\
\mathrm{~cm}-17 \mathrm{~cm}\end{array}$ & $\begin{array}{l}\text { Memenuhi } \\
\text { standar }\end{array}$ \\
\hline & $\begin{array}{l}\text { Kedalaman anak tangga } \\
=30 \mathrm{~cm}\end{array}$ & $\begin{array}{l}\text { Memenuhi } \\
\text { standar }\end{array}$ \\
\hline & Ketinggian bordes $=2 \mathrm{~m}$ & $\begin{array}{l}\text { Memenuhi } \\
\text { standar }\end{array}$ \\
\hline & Tinggi railing $=90 \mathrm{~cm}$ & $\begin{array}{l}\text { Memenuhi } \\
\text { standar }\end{array}$ \\
\hline & Diameter railing $=10 \mathrm{~cm}$ & $\begin{array}{l}\text { Belum } \\
\text { memenuhi } \\
\text { standar }\end{array}$ \\
\hline
\end{tabular}




\begin{tabular}{|l|l|l|}
\hline Objek & Kondisi & Kesesuaian \\
\hline & $\begin{array}{l}\text { Jarak antar tangga 16 } \mathrm{m} \\
-19 \mathrm{~m}\end{array}$ & $\begin{array}{l}\text { Memenuhi } \\
\text { standar }\end{array}$ \\
\cline { 2 - 3 } & $\begin{array}{l}\text { Jarak pencapaian terjauh } \\
\text { ke tangga }=16 \mathrm{~m}\end{array}$ & $\begin{array}{l}\text { Belum } \\
\text { memenuhi } \\
\text { standar }\end{array}$ \\
\cline { 2 - 3 } & $\begin{array}{l}\text { Tinggi anak tangga area } \\
\text { tribun balkon }=20 \mathrm{~cm}- \\
25 \mathrm{~cm}\end{array}$ & $\begin{array}{l}\text { Belum } \\
\text { memenuhi } \\
\text { standar }\end{array}$ \\
\hline \multirow{2}{*}{ Exhaust } & $\begin{array}{l}\text { Tersedia di hampir setiap } \\
\text { sisi ruangan. }\end{array}$ & $\begin{array}{l}\text { Memenuhi } \\
\text { standar }\end{array}$ \\
\hline
\end{tabular}

(Sumber : Penulis)

Dari keempat sarana yang tersedia, menunjukkan bahwa ketersediaan pintu sebagai akses utama keluar-masuk gedung sudah cukup memenuhi standar, terutama dari segi jumlah, ukuran, perletakan, dan tanda penunjuk arah yang dapat mempengaruhi kelancaran proses evakuasi saat terjadi bencana dan bahaya kebakaran. Adapun kekurangan yang dimiliki oleh pintu GSG UNIB ini seperti tungkai pembuka dan penutup otomatis yang tidak tersedia, serta warna yang tidak sesuai dapat dimengerti karena pintu merupakan pintu utama dan bukan pintu darurat. Hal ini berarti bahwa GSG UNIB tidak memiliki pintu khusus yang bisa digunakan dalam keadaan darurat. Selain itu, material pintu juga hendaknya memenuhi persyaratan tahan api agar proses evakuasi dapat berjalan secara aman.

Ruang utama GSG UNIB memiliki bentuk open layout, dan ruangan sedang tidak digunakan saat dilakukan pengamatan, membuat area jalur evakuasi dapat dikatakan telah memenuhi standar karena tidak terhalangi oleh benda yang dapat mengganggu kelancaran proses evakuasi. Meskipun demikian, himbauan kepada pengguna bangunan nantinya tetap diperlukan agar penyusunan perabot terutama di lantai dasar tidak menghalangi akses ke luar. Ketersediaan beberapa alat seperti tombol alarm kebakaran, lampu darurat, hidran, sprinkler, tabung pemadam, serta detektor, panas, asap dan api perlu dihadirkan untuk meningkatkan keamanan dan kelancaran proses evakuasi.

Jalur evakuasi berupa tangga, secara umum telah memenuhi standar terutama dari segi bentuk, dimensi, dan perletakannya yang menyebar. Hanya saja, tangga di area tribun masih belum memenuhi standar karena ketinggian anak tangga yang melebihi standar. Selain itu, diameter railing yang terlalu besar, dan terdapat dua buah railing yang salah satu sisinya menempel dinding, dapat mengurangi kenyaman dan dapat mengganggu kelancaran proses evakuasi. Pada area sudut balkon di lantai 2, jarak terjauh untuk mencapai tangga melebih standar yang ditetapkan. Tidak tersedianya pintu yang langsung mengarah ke luar di balkon lantai 2, membuat semua pengguna bangunan harus melalui tangga dan bertumpuk di area tangga terlebih dahulu sebelum ke luar bangunan. Hal ini dapat menghambat kelancaaran proses evakuasi dan menyebabkan tertumpunya jalur evakuasi di 3 akses pintu dengan bukaan yang lebar di lantai dasar. Meskipun demikian, terdapat kemungkinan.

untuk memberikan akses tambahan di sudut balkon lantai 2 berupa pintu darurat tambahan yang langsung menuju ke luar dan telah terdapat tangga di bagian belakang bangunan. Adapun tangga di bagian belakang gedung hanya difungsikan sebagai tangga menuju ruang-ruang kecil untuk kegiatan mahasiswa di bagian belakang lantai 2 GSG UNIB. Tidak tersedianya pintu akses ke luar di lantai 2 bisa dipahami untuk untuk keamanan saat GSG UNIB digunakan untuk acara ertentu.

\section{KESIMPULAN}

Secara garis besar, jalur evakuasi bencana kebakaran pada sirkulasi Gedung Serba Guna Universitas Bengkulu sudah cukup memenuhi standar. Tersedianya tangga yang menyebar di ruangan utama, pintu yang lebar disertai tanda "EXIT", dan adanya exhaust di hampir setiap 
sisi ruangan merupakan nilai unggul dalam kesiapan GSG UNIB menghadapi bahaya kebakaran. Meskipun demikian, setiap sarana yang tersedia masih memiliki beberapa kekurangan yang belum memenuhi standar. Hal ini dapat ditolelir karena standar yang tersedia tidak secara spesifik ditujukan untuk bangunan luas yang open layout, melainkan ditujukan untuk bangunan gedung secara umum.

Adapun perlatan yang perlu untuk disediakan adalah tabung pemadam untuk mendukung keamanan saat terjadinya bencana kebakaran. Walau pencahyaan alami di GSG UNIB pada siang hari telah memadai, ketersediaan lampu darurat juga dibutuhkan untuk mengatisipasi pada saat kondisi gelap.

Masukan lain yang diusulkan adalah penambahan pintu yang langsung menuju ke arah luar ruangan di lantai 2 untuk menghindari terjadinya penumpukan di area tangga saat proses evakuasi. Tentunya hal ini perlu dilakukan penlitian lebih lanjut untuk mengetahui keefektifan durasi waktu evakuasi.

CATATAN. Penelitian merupakan kegiatan hibah Fakultas Teknik Universitas Bengkulu. Ucapan terimakasih penulis sampaikan pula kepada pihak Universitas Bengkulu yang memberikan kesempatan untuk melakukan survey di GSG UNIB.

\section{DAFTAR PUSTAKA}

Andhika, Praditha Khalis; Kasim, Fadli; \& Hawibowo Singgih. (2013). "Optimasi Proses Evakuasi dalam Menghadapi Situasi Darurat Pada Gedung Graha Sabha Pramana (Studi Kasus Acara Wisuda)". Teknofisika Vol.2, No.2, Hal : 25-41.

Frick, Heinz; Ardiyanto Antonius; \& Darmawan AMS. (2008). Ilmu Fisika Bangunan. Penerbit Kansius. Yogyakarta.

Jimmy S, Juwana. (2005). Panduan Sistem Bangunan Tinggi Untuk Arsitek dan Praktisi Bangunan. Penerbit Erlangga. Jakarta.

Kowara, Rigen Adi; \& Martiana, Tri. (2017). “Analisis Sistem Proteksi Kebakaran Sebagai Upaya Pencegahan Dan Penanggulangan Kebakaran”. Jurnal Manajemen Kesehatan RS Dr. Soetomo Vol.3, No.1, Hal : 70-85.

PerMen PU 26/08. Peraturan Menteri Pekerjaan Umum Nomor 26/PRT/M/2008 tentang Persyaratan Teknis Sistem Proteksi Kebakaran Pada Bangunan Gedung dan Lingkungan.

PerMen PU 45/07. Peraturan Menteri Pekerjaan Umum Nomor 45/PRT/M2007 tentang Pedoman Teknis Pembangunan Bangunan Gedung Negara.

Setiawan, Moch Fathoni; Purnomo, Andi; Santoso, Eko Budi. (2016). "Evaluasi Fungsi Tangga Darurat pada Gedung-gedung di Universitas Negeri Semarang". Prosiding Temu Ilmiah IPLBI, Hal :55-60.

Soemitro, R.A.A. \& Suprayitno, H. (2018). "Pemikiran Awal tentang Konsep Dasar Manajemen Aset Fasilitas". Jurnal Manajemen Aset Infrastruktur \& Fasilitas, Vol. 2, Sup. 1, Juni 2018, Hal : 1-13.

SNI 03-1746-2000. Standar Nasional Indonesia 03-1746-2000. Tata cara perencanaan dan pemasangan sarana jalan ke luar untuk penyelamatan terhadap bahaya kebakaran pada bangunan gedung.

SNI 03-6574-2001. Standar Nasional Indonesia 03-6574-2001. Tata Cara Perancangan Pencahayaan Darurat, Tanda arah dan Sistem Peringatan Bahaya paada Bangunan Gedung.

Suprayitno, H. \& Soemitro, R.A.A. (2018). "Preliminary Reflexion on Basic Principle of Infrastructure Asset Management". Jurnal Manajemen Aset Infrastruktur \& Fasilitas, Vol. 2, No. 1, Maret 2018, Hal : 1-9. 